\title{
Correction to: 2-Pentadecyl-2-oxazoline ameliorates memory impairment and depression-like behaviour in neuropathic mice: possible role of adrenergic alpha2- and $\mathrm{H} 3$ histamine autoreceptors
}

\author{
Serena Boccella ${ }^{1 \dagger}$, Francesca Guida $^{1 \dagger}$, Monica lannotta ${ }^{1 \dagger}$, Fabio Arturo lannotti ${ }^{3,4 \dagger}$, Rosmara Infantino ${ }^{1}$, \\ Flavia Ricciardi ', Claudia Cristiano², Rosa Maria Vitale ${ }^{3}$, Pietro Amodeo ${ }^{3}$, Ida Marabese ${ }^{1}$, Carmela Belardo ${ }^{1}$, \\ Vito de Novellis' ${ }^{1}$, Salvatore Paino ${ }^{1}$, Enza Palazzo ${ }^{1}$, Antonio Calignano², Vincenzo Di Marzo ${ }^{3,4,5}$, \\ Sabatino Maione ${ }^{1,4,6}$ and Livio Luongo $0^{1,4,6^{*}}$ (D)
}

\section{Correction to: Mol Brain (2021) 14:28} https://doi.org/10.1186/s13041-020-00724-z Following publication of the original article [1], the authors identified multiple errors throughout the article. The corrected errors are listed below and the original article has been updated to correct this.

\section{Abstract section}

The second-to-last sentence of the Abstract was corrected. The updated sentence is given below and the changes have been highlighted in bold typeface:

Treatment for 14 days with PEA-OXA after the onset of the symptoms associated with neuropathic pain resulted in the following effects: (i) allodynia was decreased; (ii) affective/cognitive impairment associated with SNI (depression, spatial, and working memories)

The original article can be found online at https://doi.org/10.1186/s13041 020-00724-z

\section{*Correspondence: livio.luongo@gmail.com}

†'Serena Boccella, Francesca Guida, Monica lannotta and Fabio Arturo lannotti share the first authorship

${ }^{1}$ Department of Experimental Medicine, Pharmacology Division, University of Campania "L. Vanvitelli", 80138 Naples, Italy

Full list of author information is available at the end of the article was counteracted; (iii) long-term potentiation in vivo in the lateral entorhinal cortex-dentate gyrus (perforant pathway, LPP) was ameliorated, (iv) hippocampal glutamate, GABA, histamine, norepinephrine and dopamine altered levels after peripheral nerve injury were reversed, (v) expression level of the $\mathrm{TH}$ positive neurons in the Locus Coeruleus were normalized.

\section{Figure 1 caption}

The first few sentences of the caption for Fig. 1 were corrected. The updated caption is given below and the changes have been highlighted in bold typeface:

Alpha2-mediated effect of PEA-OXA in vitro and in vivo. (a) Scatter plots showing the effect of PEAOXA in COS cells stably expressing histamine H3 receptors on intracellular cAMP levels. Forskolin $10 \mathrm{uM}$ served as AMPc inducer. Data represent the mean \pm S.E.M. of four separate determinations. Data sets were compared using t-Test and ANOVA followed by Tukey's test. The asterisk indicates a $p$ value $\leq 0.05$ vs vehicle. The symbol $( \pm)$ indicates a $p$ value $\leq 0.05$ vs forskolin. The symbol $\left({ }^{\circ}\right)$ indicates a $\mathrm{p}$ value $\leq 0.05$ vs histamine. Effects of single injection of PEA-OXA $(2.5 \mathrm{nmol} / 0.3 \mu \mathrm{l}$ i.c.v. $)$ on Immepip-induced decreased original author(s) and the source, provide a link to the Creative Commons licence, and indicate if changes were made. The images or other third party material in this article are included in the article's Creative Commons licence, unless indicated otherwise in a credit line to the material. If material is not included in the article's Creative Commons licence and your intended use is not permitted by statutory regulation or exceeds the permitted use, you will need to obtain permission directly from the copyright holder. To view a copy of this licence, visit http://creativecommons.org/licenses/by/4.0/. The Creative Commons Public Domain Dedication waiver (http://creativeco mmons.org/publicdomain/zero/1.0/) applies to the data made available in this article, unless otherwise stated in a credit line to the data. 
locomotor activity in into third ventricle (I3V) of Naïve mice (b, c). Representation of coronal sections of the mouse brain with the cannula placement in I3V (b), Representative traces of mouse movement during an open field test (c upper panel). Total distance traveled in OFT (c lower panel). Data are represented as mean \pm SEM of 5 mice per group. ${ }^{* *} \mathrm{p}<0.01$ and ${ }^{\# \# \#} \mathrm{p}<0.001$ indicate significant differences compared to ACSF or Immepip. One-Way ANOVA, followed by Holm-Sidak's post hoc test for multiple comparisons test was performed. Effect of the chronic treatment with vehicle (kolliphor
$5 \%$ in saline, v/v, i.p.) or PEA-OXA (10 mg/kg, i.p.) on the Histamine release in the hippocampus CA3 (d). Data are represented as mean \pm SEM of 8 mice per group. Two-way ANOVA, followed by Tukey's post hoc test for multiple comparisons test were used for statistical analysis. $\mathrm{p}<0.05$ was considered statistically significant. Symbols indicate significant differences: ${ }^{* * * *}$ vs Sham/veh $(\mathrm{p}<0.0001)$ and ${ }^{\# \#}$ vS SNI/veh $(\mathrm{p}<0.001)$, respectively.

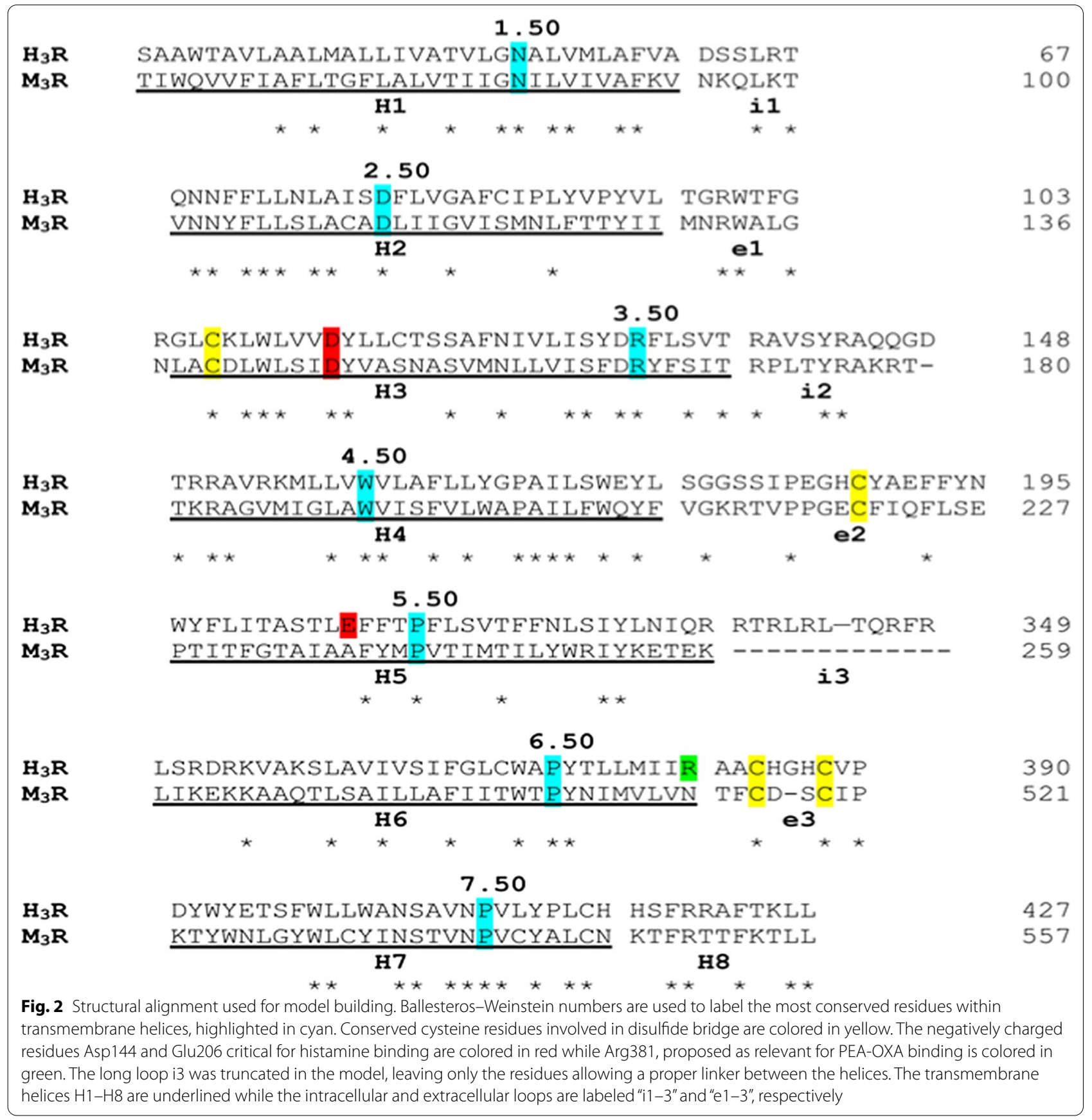



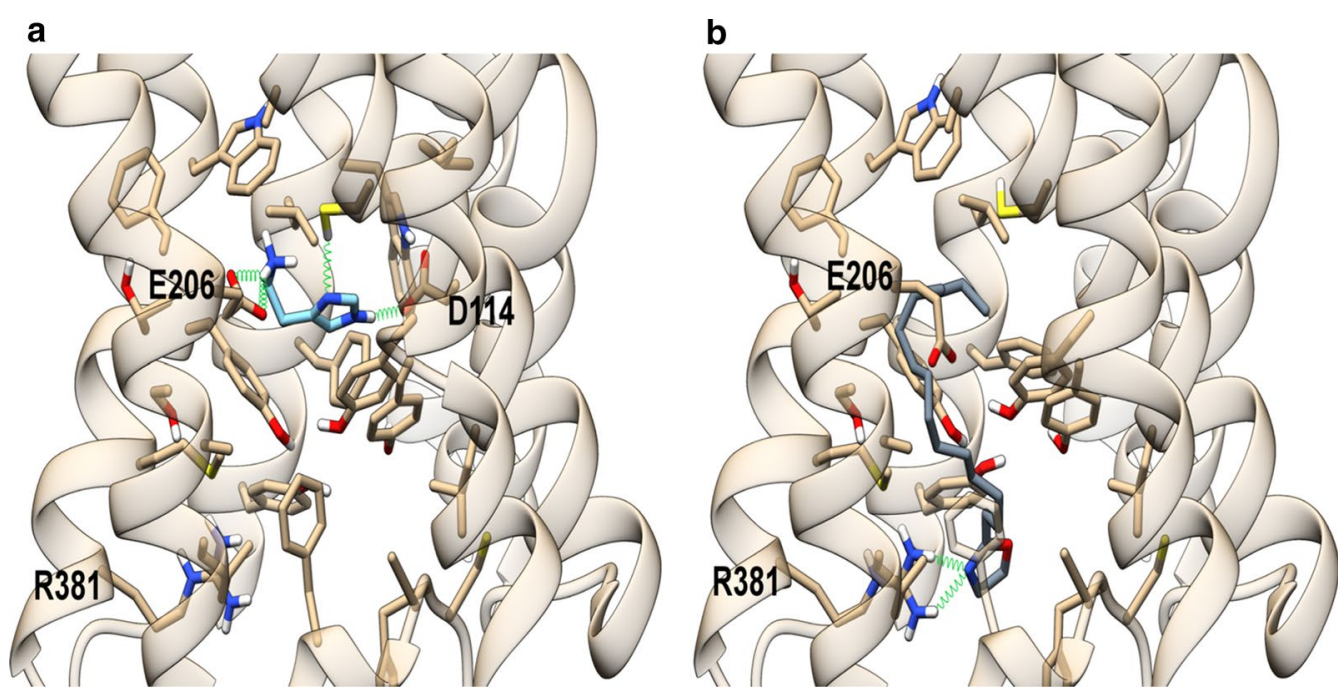

Fig. 3 Energy minimized theoretical complexes of histamine $\mathrm{H} 3$ receptor with histamine (a) and PEA-OXA (b). Protein is colored in tan, histamine in light blue and PEA-OXA in slate gray. Ligands and residues within $5 \AA$ from the ligands are shown in stick representation. Oxygen, sulfur and nitrogen heteroatoms are colored in red, yellow and blue, respectively. H-bonds are represented as green springs

\section{Figures 2 and 3}

Figures 2 and 3 were interchanged. The captions for these figures were captured correctly, but the Figures itself were interchanged. The correct figures and captions have been included.

\section{Theoretical complexes of the human histamine H3 receptor with histamine and PEA-OXA section}

In the second-to-last sentence of the 'Theoretical complexes of the human histamine $\mathrm{H} 3$ receptor with histamine and PEA-OXA' section, the citation to Fig. 3 was removed.

\section{PEA-OXA pharmacological modulation of histamine $\mathrm{H} 3$ receptor: in vitro and in vivo evidence section}

In the last sentence of the first paragraph of the 'PEAOXA pharmacological modulation of histamine $\mathrm{H} 3$ receptor: in vitro and in vivo evidence' section, the word 'positive' was removed before 'allosteric modulator. The corrected sentence reads:

We cannot exclude that PEA-OXA might behave as a allosteric modulator of the $\mathrm{H} 3$ receptors as also suggested by the docking data.

\section{Author details}

${ }^{1}$ Department of Experimental Medicine, Pharmacology Division, University of Campania "L. Vanvitelli", 80138 Naples, Italy. ${ }^{2}$ Department of Pharmacy, School of Medicine, University of Naples Federico II, Naples, Italy. ${ }^{3}$ Institute of Biomolecular Chemistry, CNR, Pozzuoli, Italy. ${ }^{4}$ Endocannabinoid Research Group, Institute of Biomolecular Chemistry, CNR, Pozzuoli, Italy. ${ }^{5}$ Canada Excellence Research Chair on the Microbiome-Endocannabinoidome Axis in Metabolic Health, Université Laval, Quebec City, Canada. ${ }^{6}$ IRCSS, Neuromed, Pozzilli, Italy.

Published online: 01 April 2021

\section{Reference}

1. Boccella S, Guida F, lannotta M, lannotti FA, Infantino R, Ricciardi F, Cristiano C, Vitale RM, Amodeo P, Marabese I, Belardo C, de Novellis V, Paino S, Palazzo E, Calignano A, Di Marzo V, Maione S, Luongo L. 2-Pentadecyl2-oxazoline ameliorates memory impairment and depression-like behaviour in neuropathic mice: possible role of adrenergic alpha2- and H3 histamine autoreceptors. Mol Brain. 2021;14:28. https://doi.org/10. 1186/s13041-020-00724-z.

\section{Publisher's Note}

Springer Nature remains neutral with regard to jurisdictional claims in published maps and institutional affiliations. 